\title{
Mental health services, suicide and 7-day working
}

\author{
Nav Kapur, Saied Ibrahim, Isabelle M. Hunt, Pauline Turnbull, Jenny Shaw and Louis Appleby
}

\section{Background}

Patients admitted to hospital at the weekend appear to be at increased risk of death compared with those admitted at other times. However, a 'weekend effect' has rarely been explored in mental health and there may also be other times of year when patients are vulnerable.

\section{Aims \\ To investigate the timing of suicide in high-risk mental health patients.}

\section{Method}

We compared the incidence of suicide at the weekend $\mathrm{v}$. during the week, and also in August (the month of junior doctor changeover) $v$. other months in in-patients, patients within 3 months of discharge and patients under the care of crisis resolution home treatment (CRHT) teams (2001-2013).

\section{Results}

The incidence of suicide was lower at the weekends for each group (incidence rate ratio (IRR) $=0.88(95 \% \mathrm{Cl} 0.79-0.99)$ for in-patients, IRR $=0.85$ (95\% Cl 0.78-0.92) for post-discharge patients, IRR $=0.87$ ( $95 \% \mathrm{Cl} 0.78-0.97$ ) for CRHT patients).

Patients who died by suicide were also less likely to have been admitted at weekends than during the week (IRR $=0.52$ (95\% Cl 0.45-0.60)). The incidence of suicide in August was not significantly different from other months.

\section{Conclusions}

We found evidence of a weekend effect for suicide risk among high-risk mental health patients, but with a 12-15\% lower incidence at weekends. Our study does not support the claim that safety is compromised at weekends, at least in mental health services.

\section{Declaration of interest}

N.K. is partly supported by Manchester Mental Health and Social Care Trust. N.K. chaired the guideline development group for the 2012 NICE guidelines on the longer-term management of self-harm and currently chairs the guideline development group for the NICE depression in adults guideline. L.A. chairs the Suicide Prevention Advisory Group at the Department of Health (of which N.K. is also a member) and is a non-executive Director for the Care Quality Commission.

\section{Copyright and usage}

(c) The Royal College of Psychiatrists 2016.
There is evidence that patients who are admitted to hospital at the weekend are at increased risk of dying compared with patients admitted at other times, ${ }^{1-5}$ but the reasons for this are unclear. ${ }^{6}$ In England it has been suggested that the 'weekend effect' could account for 6000 excess deaths per year. ${ }^{7}$ One explanation relates to reduced hospital staffing on Saturday and Sunday, and it has been argued that some deaths could be prevented if patients had continual access to high-quality care. A '7-day National Health Service' (NHS) is currently a policy priority in the UK. ${ }^{8}$ However, it is likely that the potential for prevention varies from speciality to speciality and between settings. ${ }^{6}$ Previous studies have examined mortality following any admission, ${ }^{3}$ emergency and elective surgical admission $^{5}$ and after stroke, ${ }^{1}$ but the weekend effect is a relatively unexplored phenomenon in mental health. A study carried out in a single London hospital suggested no increase in all-cause mortality for patients admitted to a psychiatric bed at the weekend. ${ }^{2}$ Suicide is a key outcome for mental health services, ${ }^{9}$ and has previously been used as a marker of the quality and safety of care. ${ }^{10}$ Some groups of patients, such as current or recent in-patients, ${ }^{11,12}$ or those receiving intensive treatment at home as an alternative to admission, ${ }^{13}$ are at particularly high risk of dying by suicide.

In this study we investigated the timing of suicide in a national patient sample. Temporal variations in suicide by season of the year or day of the week have been investigated in a number of studies previously. ${ }^{14-16}$ However, our aim in this study was not to describe the timing of suicide in the general population, but to examine the specific weekend $v$. weekday incidence of suicide in very high-risk patient groups who might be most vulnerable to changes in service provision. We hypothesised that a weekend effect would manifest itself as an increased incidence of suicide on Saturday and Sunday compared with other days of the week. Another point in the calendar where there may be significant staffing disruption is the changeover point for junior doctors, ${ }^{17}$ particularly in August in the UK when many start work for the first time. We hypothesised that an August effect might result in a higher incidence of patient suicide in that month compared with others.

\section{Method}

\section{Data acquisition}

Suicide data were collected as part of the National Confidential Inquiry into Suicide and Homicide by People with Mental Illness (NCISH) ${ }^{18}$ Data collection has been described in detail elsewhere. ${ }^{19}$ Briefly, it occurred in three stages. First, national data on people who had died by suicide in the general population in England were obtained from the Office of National Statistics. Second, NHS mental health services identified which of these individuals had been in contact with services in the 12 months before death. These trusts also identified the clinician who had been caring for the patient prior to their suicide. Third, detailed questionnaires were sent to the clinicians to obtain demographic and clinical data (including care at the time of death). Case ascertainment is relatively complete with a response rate for questionnaires of over $95 \% .{ }^{19}$

Deaths that received either a suicide or open verdict at coroner's inquest were considered to be suicide deaths in the current study, as is the convention in suicide research in the UK. Not including open verdict deaths has been shown to underestimate the number of suicides by up to $50 \% .^{20,21}$ Both the cases that received a suicide verdict and those that received an open verdict are collectively referred to as 'suicides' in the rest of this paper. 


\section{Study sample}

The present study included individuals aged 10 years and over who died by suicide between 2001 and 2013 in England. The National Confidential Inquiry does not collect data on young children, where intentions and motivations may be difficult to establish. ${ }^{19}$ Previous studies of acute hospital mortality have used data collected over a single financial year, ${ }^{3}$ but because of the comparative rarity of suicide as an outcome we used data collected over a longer period. Some groups of patients with mental health disorders are at particularly high risk of suicide. They include psychiatric in-patients and those recently discharged from in-patient care, ${ }^{11,12}$ and those under the care of crisis resolution home treatment (CRHT) teams (a service intended as an alternative to admission). ${ }^{13}$ These groups are in close proximity to care and may be more affected by weekend changes to staffing or service availability than other patients. We therefore chose to focus on them in the current study.

\section{Main outcome}

Our main outcome was risk of suicide in relation to day of death. Previous investigations of the weekend effect in hospital settings have examined the risk of death by day of admission. ${ }^{3}$ Suicide commonly occurs in the context of complex difficulties, but the final act may be relatively impulsive and in response to an acute stressor. $^{22}$ Care at the time of death may therefore be a more important determinant of outcome than care at the time of admission. In addition, lengths of stay for in-patient mental health services are much longer than for acute medical or surgical specialities, ${ }^{23}$ and so care immediately following admission may be less critical in terms of mortality risk.

\section{Statistical analysis}

We initially examined the timing of suicide by day of the week. We expressed the incidence of suicide as the number of suicide deaths per 100 days at risk (for example, the number of suicide deaths on a Monday per 100 Mondays at risk throughout the study period or the number of suicide deaths in January per 100 January days at risk). Suicide deaths are statistically rare events that can generally be expected to follow a Poisson distribution. Consequently, Poisson regression models were fitted with the number of suicides on each day as the dependent variable. Models were tested for overdispersion (where variation is high and violates the use of a Poisson model), and if this was evident, negative binomial regression models were fitted to account for high variation. The use of these models allowed the calculation of incidence rate ratios (IRRs) with 95\% confidence intervals, comparing the suicide incidence at the weekend with the suicide incidence during the working week. $P$-values less than $5 \%$ were considered significant. Levels of missing data were low - only two patients in the whole sample did not have details of the care they had been receiving at the time of death.

Although our main focus was on risk of suicide in relation to day of the week, we did also examine the risk of suicide by day of admission for the in-patient sample only. In order to investigate a possible August effect we examined the timing of suicide by month of the year. The 'August effect' (or its USA counterpart, the 'July effect') refers to the possible reduction in the quality and safety of care when final-year medical students become doctors and junior doctors become a grade more senior. ${ }^{17,24}$ There are other potential transition points, but the summer one is the best described and some of the other changeovers in the UK (for example every 4 months) are comparatively recent developments (post 2005).

\section{Results}

Over the study period there were 1621 in-patient suicide deaths, 2819 suicide deaths within 3 months of in-patient discharge and 1765 deaths under CRHT teams. Although in-patients were a distinct group, $592(21 \%)$ of the post-discharge deaths were also under CRHT. Table 1 shows demographic and clinical characteristics of the patients.

Figure 1 shows the timing of suicide in relation to day of the week. There was a significant difference in the incidence of suicide between weekdays and weekends for all patient groups, with a lower suicide risk at weekends (in-patients: IRR $=0.88(95 \% \mathrm{CI}$ $0.79-0.99)$; post-discharge patients: IRR $=0.85$ (95\% CI 0.78-0.92); patients under CRHT: IRR $=0.87$ (95\% CI 0.78-0.97)).

Figure 2 shows the timing of suicide in relation to month of the year. There was no evidence of an August peak in suicide. The peak month for incidence of suicide was May for in-patients, September for post-discharge patients and November for CRHT team patients.

\section{Table 1 Demographic and clinical characteristics of the patients who died by suicide between 2001 and 2013 in the study}

\begin{tabular}{|c|c|c|c|}
\hline Characteristics & $\begin{array}{c}\text { In-patients } \\
(n=1621)\end{array}$ & $\begin{array}{l}\text { Within } 3 \text { months } \\
\text { of discharge } \\
(n=2819)\end{array}$ & $\begin{array}{c}\text { Under care of CRHT } \\
\text { team } \\
(n=1765)\end{array}$ \\
\hline Age, median (range) & $44(15-96)$ & $45(15-95)$ & $48(15-95)$ \\
\hline \multicolumn{4}{|l|}{ Gender, $n(\%)$} \\
\hline Male & $1031(64)$ & $1800(64)$ & $1082(61)$ \\
\hline Female & $590(36)$ & $1019(36)$ & 683 (39) \\
\hline \multicolumn{4}{|l|}{ Primary diagnosis, $n$ (\%) } \\
\hline Schizophrenia and other delusional disorders & $483(30)$ & $455(16)$ & 229 (13) \\
\hline Bipolar affective disorder & $190(12)$ & $300(11)$ & $161(9)$ \\
\hline Depressive illness & $602(37)$ & $990(35)$ & $845(48)$ \\
\hline Other diagnosis & $346(21)$ & $1074(38)$ & $530(30)$ \\
\hline \multicolumn{4}{|l|}{ Method, $n(\%)$} \\
\hline Hanging/strangulation & $728(45)$ & $1175(42)$ & $813(46)$ \\
\hline Self-poisoning & $143(9)$ & $644(23)$ & $357(20)$ \\
\hline Other methods & $750(46)$ & $1000(35)$ & $595(34)$ \\
\hline History of self-harm, $n$ (\%) & $1227(76)$ & $2124(75)$ & $1223(69)$ \\
\hline History of drug and/or alcohol misuse, $n$ (\%) & 759 (47) & $1492(53)$ & $743(42)$ \\
\hline
\end{tabular}


(a)

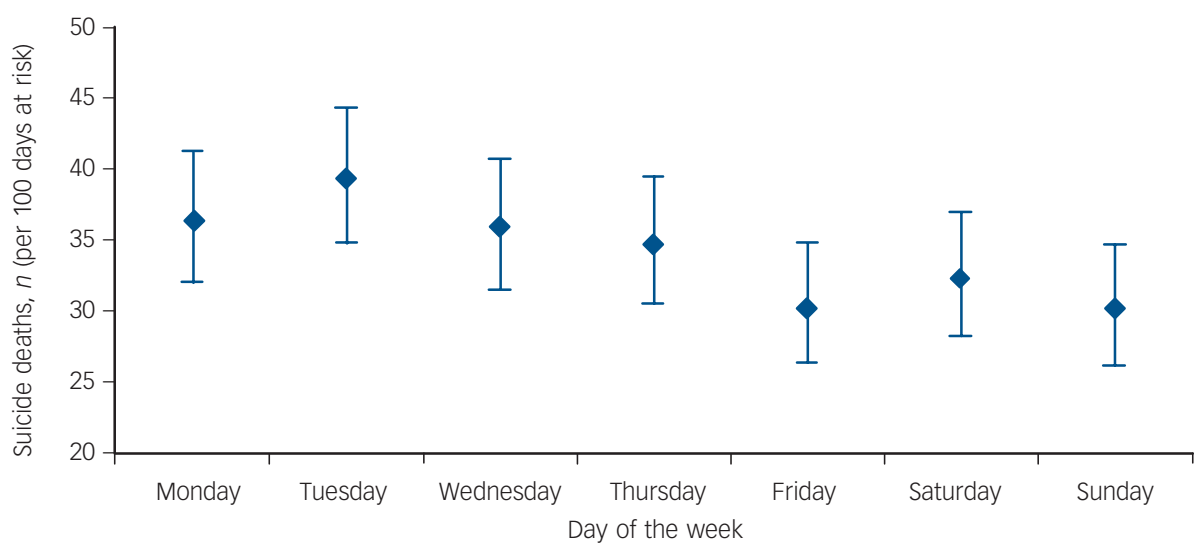

(b)

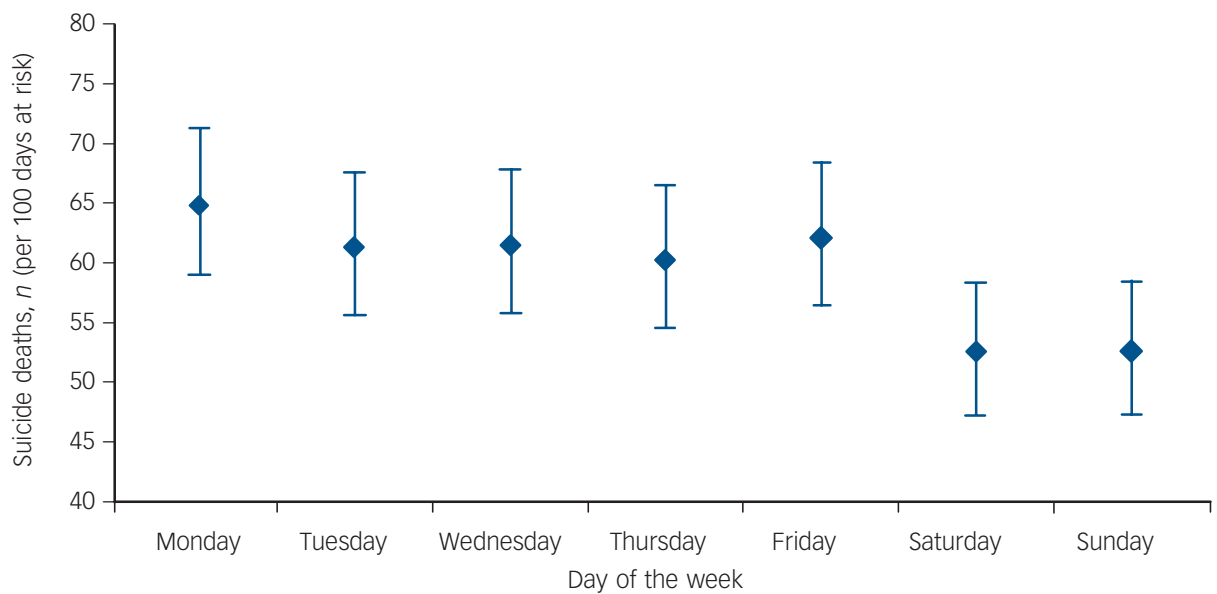

(c)

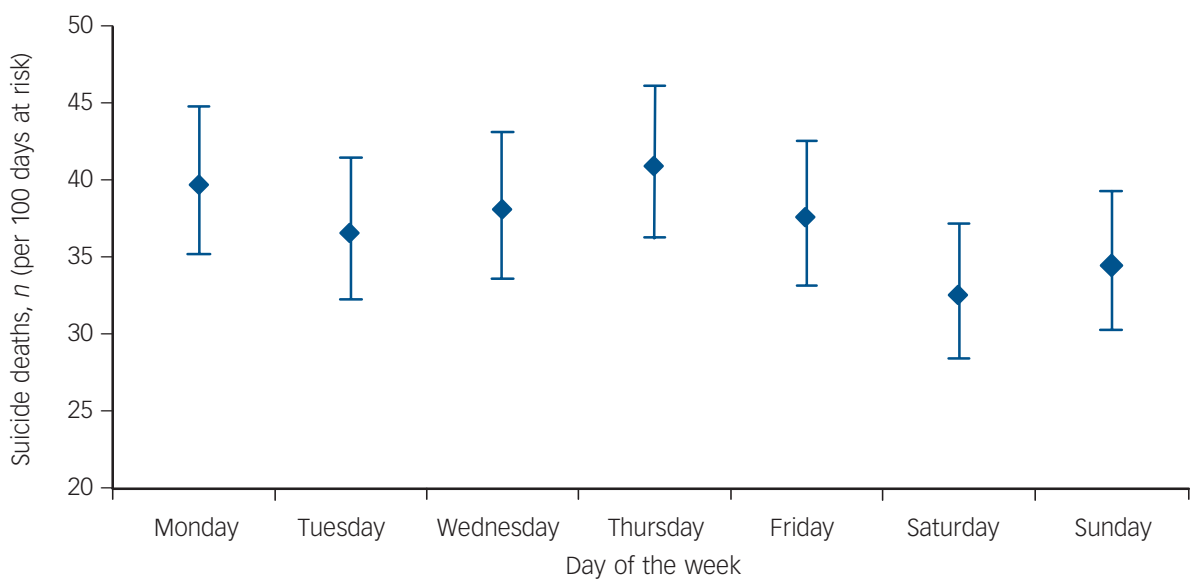

\section{Fig. 1 Patient suicide in England by day of the week (2001-2013).}

(a) In-patients: weekend $v$. weekday incidence rate ratio (IRR) $=0.88,95 \% \mathrm{Cl} 0.79-0.99, P=0.03$. (b) Post-discharge patients (suicide within 3 months of in-patient discharge): weekend $v$. weekday IRR $=0.85,95 \% \mathrm{Cl} 0.78-0.92, P<0.001$. (c) Patients under crisis resolution home treatment (CRHT): weekend $v$. weekday IRR $=0.87,95 \% \mathrm{Cl} 0.78-0.97, P=0.01$

Figure 3 shows the timing of suicide in psychiatric in-patients in relation to day of admission. Patients who died by suicide were less likely to have been admitted to hospital on a Saturday or Sunday than during the week (IRR $=0.52$ (95\% CI $0.45-0.60)$, $P<0.001)$. We obtained similar findings when we restricted the analysis to people who had died within 30 days of admission: IRR weekend $v$. weekdays $=0.65(95 \%$ CI $0.54-0.78), P<0.001$; or people who had died within 7 days of admission: IRR weekend $v$. weekdays $=0.70(95 \%$ CI $0.53-0.94), P=0.02$.

\section{Discussion}

\section{Main findings}

We found clear evidence of a weekend effect for suicide deaths among mental health patient groups, but contrary to our hypothesis, the incidence of suicide was actually $12-15 \%$ lower at the weekend. Similarly, when we re-ran our analysis for in-patients only based on the day of admission, the incidence of suicide for 
(a)

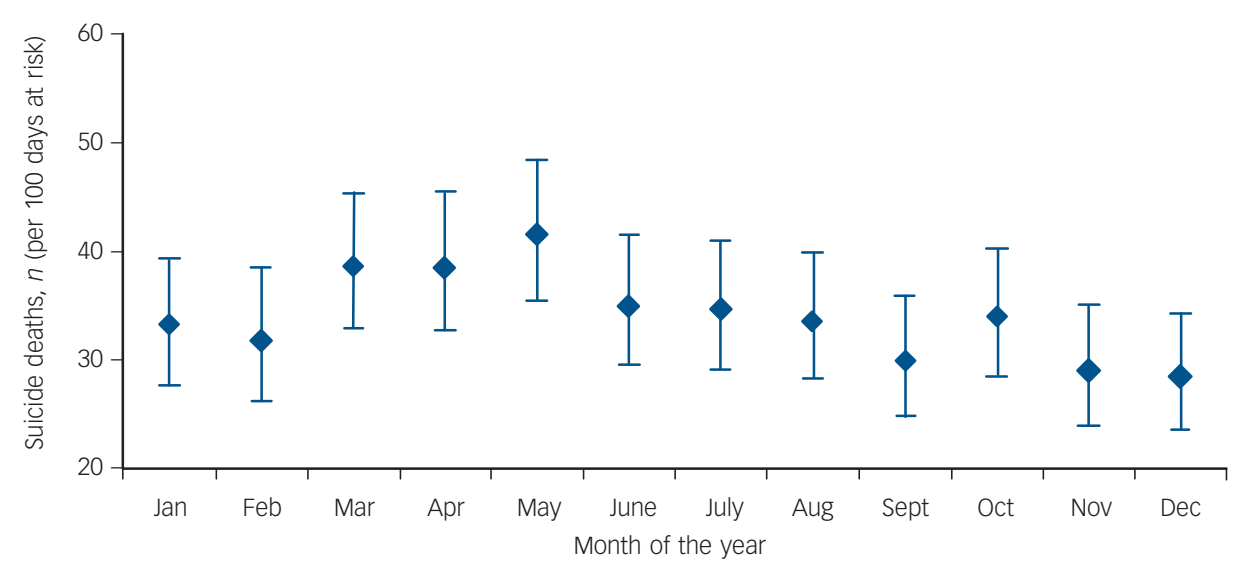

(b)

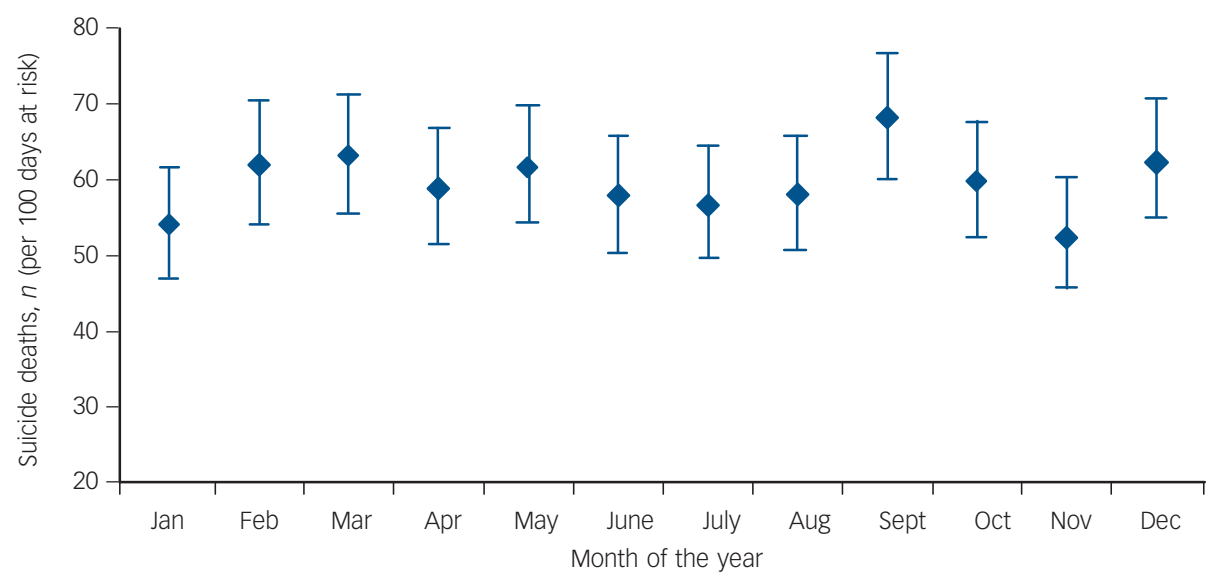

(C)

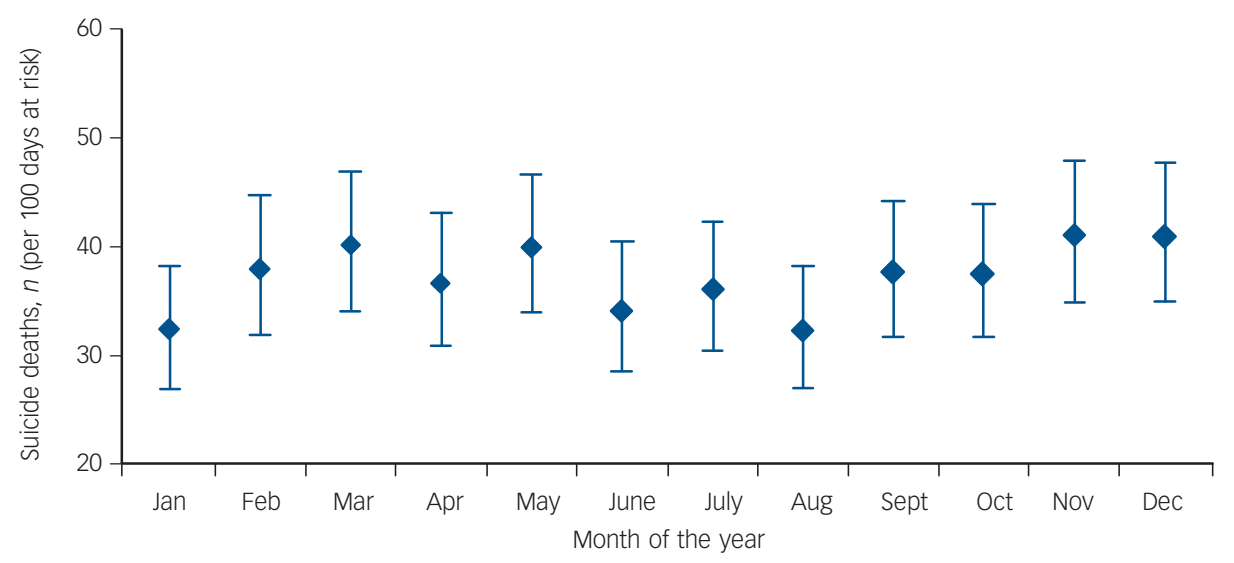

Fig. 2 Patient suicide in England by month of year (2001-2013).

(a) In-patients: August $v$. other months incidence rate ratio (IRR) $=0.99,95 \% \mathrm{Cl} 0.83-1.18, P=0.93$. (b) Post-discharge patients (suicide within 3 months of in-patient discharge): August $v$. other months IRR $=1.01,95 \% \mathrm{Cl} 0.88-1.15, P=0.90$. (c) Patients under crisis resolution home treatment (CRHT): August $v$. other months IRR $=1.14,95 \% \mathrm{Cl} 0.96-1.37, P=0.14$.

patients admitted on a Saturday or Sunday was much lower than for those admitted during the week. We found no evidence for an August peak in suicide related to the changeover of junior doctors.

\section{Strengths and limitations}

Our study involved national data collection with excellent coverage, but our findings need to be interpreted in the context of a number of methodological limitations, the most important of which is the purely descriptive design. We were, of course, unable to investigate causal mechanisms using this approach. We did not adjust for potential case mix differences as our analyses were based on people who had died by suicide rather than an at-risk cohort. It is therefore possible, although we think unlikely, that our findings are the result of patients under mental healthcare at the weekend being at lower risk than patients during the working week. The reduced IRRs could reflect fewer people under mental healthcare at the weekend, but in-patients on weekend leave would be captured in our figures (and in fact the proportion of in-patients who died while on agreed leave at weekends and during the week was similar $(56 \%$ v. $52 \%$, $\left.\chi^{2}=1.69, P=0.19\right)$ ). Of course if many more patients were formally discharged from in-patient wards on a Friday this might partly account for the findings, but this would not apply to 


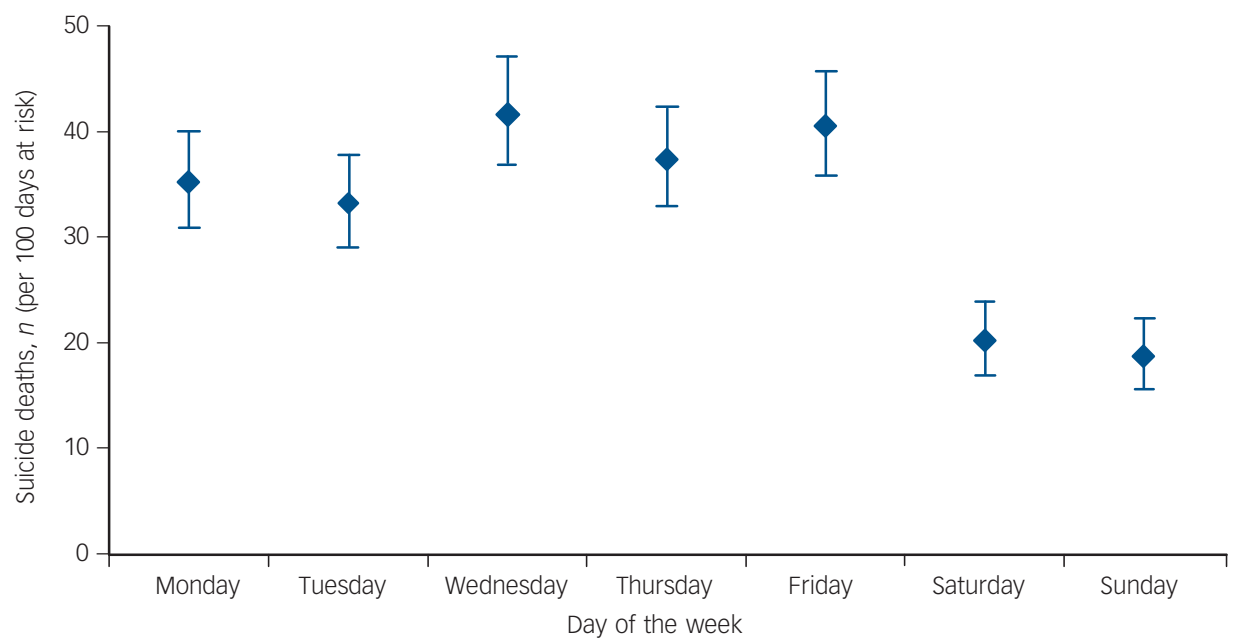

Fig. 3 Suicide in England by day of admission (in-patients 2001-2013).

post-discharge or community patients or our analysis based on day of admission.

Another potential weakness is that we considered the day of death as our main outcome rather than the day of the actual episode of suicidal behaviour. Self-poisoning is one method of suicide for which there may be a lag between the suicide episode and death. However, when we ran additional analyses, we found no significant difference in the temporal pattern of suicide by different methods (interaction terms for self-poisoning $v$. other methods were non-significant). It is also possible that some deaths were not discovered until after the weekend and so an inaccurate date of death was recorded on the death certificate. However, this is unlikely to apply to the in-patients and patients under the care of home treatment teams (who should have been seen by staff on a frequent basis) or to post-discharge patients who lived with others (around half the post-discharge sample).

\section{Interpretation of findings}

How might we explain our findings? If reduced medical staffing does indeed account for the weekend effect in acute medical and surgical specialities, ${ }^{5,6}$ it may be that mental health is relatively protected from this because it is more community focused, more multidisciplinary in nature and perhaps less reliant on on-call medical staff out of hours. It could also be that increased social contact with families and others at weekends helps prevent some suicide deaths at this time. ${ }^{25}$ It is also worth noting that some previous studies that reported an elevated mortality related to weekend hospital admission actually found a slightly reduced weekend mortality among people who remained in-patients that is consistent with our study. ${ }^{26}$

The much lower incidence of suicide in people admitted at the weekend in our study is interesting. It could relate to a possible reduced threshold for admission in the absence of high-quality weekend cover in community services, which results in 'lower-risk' patients being admitted. A recent paper that suggests shorter admissions for patients admitted to a psychiatric bed at the weekend is consistent with this. ${ }^{2}$

Suicide is a complex phenomenon with a variety of causes, and another explanation for our findings could be that wider societal and environmental factors are more important determinants of suicide than mental health service provision. However, aspects of psychiatric services can be related to suicide, ${ }^{10}$ and we have previously shown an association between staffing turnover and suicide rates in UK mental health services. ${ }^{27}$ The patients included in this study had high levels of morbidity and need - the majority had significant psychiatric illness and a history of previous suicidal behaviour, and almost half had a history of alcohol or drug misuse. They died in close proximity to care, and we focused on them in the current study because they might be expected to be the groups most vulnerable to changes in care and supervision. We think it is unlikely that the drivers of temporal variation in suicide in these complex clinical groups are identical to the drivers in the general population. Nonetheless, it is possible that any service-related changes in this study were masked by the more general temporal variations in suicide. Previous general population and clinical studies have also found peaks in suicide at the beginning of the working week and in spring. ${ }^{28-32}$ However, when we ran a post hoc analysis based on all suicide deaths in the general population in England (2001-2013) we found that the weekend $v$. weekday difference was actually slightly smaller than the one we found in the clinical groups - incidence of suicide around $8 \%$ lower at the weekend in the general population $v .12-15 \%$ lower at the weekend in the patient groups (although these differences were not statistically significant when examined using tests of interaction, $P$-values ranging from 0.18 to 0.56 ).

Seven-day working for medical staff is currently a policy priority in the NHS and has a number of potential advantages, such as improving access to care, enhancing continuity of support and reducing morbidity. A key aim of such models is to improve quality and save lives. However, our study does not support the claim that safety is compromised at weekends, at least in mental health services.

Nav Kapur, FRCPsych, Centre for Suicide Prevention, Centre for Mental Health and Safety, Institute of Brain, Behaviour and Mental Health, University of Manchester and Manchester Mental Health and Social Care Trust, Manchester, UK; Saied Ibrahim PhD, Isabelle M. Hunt, PhD, Pauline Turnbull, PhD, Jenny Shaw, FRCPsych, Louis Appleby, FRCPsych, Centre for Suicide Prevention, Centre for Mental Health and Safety, Institute of Brain, Behaviour and Mental Health, University of Manchester Manchester, UK

Correspondence: Nav Kapur, Head of Suicide Research, Centre for Suicide Prevention, Centre for Mental Health and Safety, Institute of Brain, Behaviour and Mental Health, University of Manchester, Jean McFarlane Building, Oxford Road, Manchester M13 9PL, UK. Email: nav.kapur@manchester.ac.uk

First received 10 Mar 2016, final revision 27 May 2016, accepted 3 Jun 2016 


\section{Funding}

The Healthcare Quality Improvement Partnership (HQIP) commissions the Mental Health Clinical Outcome Review Programme, NCISH, on behalf of NHS England, NHS Wales, the Scottish Government Health and Social Care Directorate, the Northern Ireland Department of Health, Social Services and Public Safety (DHSSPS), and the States of Jersey and Guernsey. The views expressed in this paper are those of the authors and not the funding body. The funder had no role in the study design, data collection, data analysis, interpretation of the data or writing of the manuscript. The corresponding author had full access to all the data in the study and had final responsibility for the decision to submit for publication.

\section{Acknowledgements}

The study was part of the National Confidential Inquiry into Suicide and Homicide by People with Mental IIIness (NCISH); our thanks to the other members of the research team: Sandr Flynn, Cathryn Rodway, Alison Baird, Su-Gwan Tham, Myrsini Gianatsi, Rebecca Lowe James Burns, Philip Stones, Julie Hall, Nicola Worthington and Huma Daud.

We acknowledge the help of district directors of public health, health authority and mental health service contacts, and all respondents for completing the suicide questionnaires.

\section{References}

1 Bray BD, Cloud GC, James MA, Hemingway H, Paley L, Stewart K, et al. Weekly variation in health-care quality by day and time of admission: a nationwide, registry-based, prospective cohort study of acute stroke care. Lancet 2016; May 10 (Epub ahead of print).

2 Patel R, Chesney E, Cullen AE, Tulloch AD, Broadbent M, Stewart R, et al. Clinical outcomes and mortality associated with weekend admission to psychiatric hospital. Br J Psychiatry 2016; April 21 (Epub ahead of print).

3 Freemantle $N$, Ray $D$, McNulty $D$, Rosser $D$, Bennett $S$, Keogh $B E$, et al. Increased mortality associated with weekend hospital admission: a case for expanded seven day services? BMJ 2015; 351: h4596.

4 Aylin P. Making sense of the evidence for the "weekend effect". BMJ 2015; 351: h4652.

5 Ruiz M, Bottle A, Aylin PP. The Global Comparators project: international comparison of 30-day in-hospital mortality by day of the week. BMJ Qual Saf 2015; 24: 492-504.

6 Lilford RJ, Chen YF. The ubiquitous weekend effect: moving past proving it exists to clarifying what causes it. BMJ Qual Saf 2015; 24: 480-2.

7 McKee $M$. Is the UK government right that seven day working in hospitals would save 6000 lives a year? BMJ 2015; 351: h4723.

8 NHS England. NHS Hospital Services, Seven Days a Week. NHS England, 2016 (https://www.england.nhs.uk/ourwork/qual-clin-lead/7-day-week/).

9 Harris EC, Barraclough B. Suicide as an outcome for mental disorders. A meta-analysis. Br J Psychiatry 1997; 170: 205-28.

10 While D, Bickley H, Roscoe A, Windfuhr K, Rahman S, Shaw J, et al. Implementation of mental health service recommendations in England and Wales and suicide rates, 1997-2006: a cross-sectional and before-and-after observational study. Lancet 2012; 379: 1005-12.

11 Kapur N, Hunt IM, Windfuhr K, Rodway C, Webb R, Rahman MS, et al. Psychiatric in-patient care and suicide in England, 1997 to 2008: a longitudinal study. Psychol Med 2013; 43: 61-71.

12 Qin P, Nordentoft M. Suicide risk in relation to psychiatric hospitalization: evidence based on longitudinal registers. Arch Gen Psychiatry 2005; 62: 427-32
13 Hunt IM, Rahman MS, While D, Windfuhr K, Shaw J, Appleby L, et al. Safety of patients under the care of crisis resolution home treatment services in England: a retrospective analysis of suicide trends from 2003 to 2011. Lancet Psychiatry 2014; 1: 135-41.

14 Plöderl M, Fartacek C, Kunrath S, Pichler EM, Fartacek R, Datz C, et al. Nothing like Christmas-suicides during Christmas and other holidays in Austria. Eur J Public Health 2015; 25: 410-3.

15 Miller TR, Furr-Holden CD, Lawrence BA, Weiss HB. Suicide deaths and nonfatal hospital admissions for deliberate self-harm in the United States. Temporality by day of week and month of year. Crisis 2012; 33: 169-77.

16 Simkin S, Hawton K, Yip PS, Yam $\mathrm{CH}$. Seasonality in suicide: a study of farming suicides in England and Wales. Crisis 2003; 24: 93-7.

17 Young JQ, Ranji SR, Wachter RM, Lee CM, Niehaus B, Auerbach AD. "July effect": impact of the academic year-end changeover on patient outcomes: a systematic review. Ann Intern Med 2011; 155: 309-15.

18 Appleby L, Shaw J, Amos T. National Confidential Inquiry into Suicide and Homicide by People with Mental Illness. Br J Psychiatry 1997; 170: 101-2.

19 Windfuhr K, While D, Hunt IM, Turnbull P, Lowe R, Burns JM, et al. Suicide in juveniles and adolescents in the United Kingdom. J Child Psychol Psychiatry 2008; 49: 1155-65.

20 Linsley KR, Schapira K, Kelly TP. Open verdict $v$. suicide - importance to research. Br J Psychiatry 2001; 178: 465-8.

21 Gunnell D, Bennewith O, Simkin S, Cooper J, Klineberg E, Rodway C, et al. Time trends in coroners' use of different verdicts for possible suicides and their impact on officially reported incidence of suicide in England: 1990-2005. Psychol Med 2013; 43: 1415-22.

22 Turecki G, Brent DA. Suicide and suicidal behaviour. Lancet 2016; 387 1227-39.

23 Health and Social Care Information Centre. Hospital Episode Statistics, Admitted Patient Care, England - 2013-14. HSCIC, 2015 (http:// www.hscic.gov.uk/searchcatalogue?productid =17192).

24 Blakey JD, Fearn A, Shaw DE. What drives the 'August effect'? An observational study of the effect of junior doctor changeover on out of hours work. JRSM Short Rep 2013; 4: 1-7.

25 Bradvik L, Berglund M. A suicide peak after weekends and holidays in patients with alcohol dependence. Suicide Life Threat Behav 2003; 33 186-91.

26 Freemantle N, Richardson M, Wood J, Ray D, Khosla S, Shahian D, et al. Weekend hospitalization and additional risk of death: an analysis of inpatient data. J R Soc Med 2012; 105: 74-84.

27 Kapur N, Ibrahim S, While D, Baird A, Rodway C, Hunt IM, et al. Mental health service changes, organisational factors, and patient suicide in England in 1997-2012: a before-and-after study. Lancet Psychiatry 2016; 3: 526-34.

28 Cavanagh B, Ibrahim S, Roscoe A, Bickley H, While D, Windfuhr K, et al. The timing of general population and patient suicide in England, 1997-2012. J Affect Disord 2016; 197: 175-81.

29 Bradvik L. The occurrence of suicide in severe depression related to the months of the year and the days of the week. Eur Arch Psychiatry Clin Neurosci 2002; 252: 28-32.

30 Mann JJ, Arango V, Underwood MD. Serotonin and suicidal behavior. Ann N Y Acad Sci 1990; 600: 476-84

31 Chew KS, McCleary R. The spring peak in suicides: a cross-national analysis. Soc Sci Med 1995; 40: 223-30.

32 Ajdacic-Gross V, Bopp M, Ring M, Gutzwiller F, Rossler W. Seasonality in suicide - review and search of new concepts for explaining the heterogeneous phenomena. Soc Sci Med 2010; 71: 657-66. 